\begin{tabular}{|c|}
\hline TOTOBUANG \\
\hline Volume 9 \\
\hline
\end{tabular}

\title{
UMPATAN DALAM BAHASA JAWA DAN BAHASA LAMPUNG: KAJIAN PRAGMATIK LINTAS BUDAYA \\ (The Swearing Words in Javanese and Lampungic Language: A Study of Cross Culture Pragmatics)
}

\author{
Tri Wahyuni ${ }^{\text {a }}$ \& M. Suryadi ${ }^{b}$ \\ a \& bUniversitas Diponegoro \\ Jalan Prof. Soedarto, Tembalang, Semarang, Jawa Tengah \\ Pos-el: twahyuni99@gmail.com
}

Diterima: 9 September 2020; Direvisi: 25 Mei 2021; Disetujui: 28 Mei 2021

doi: https://doi.org/10.26499/ttbng.v9i1.247

\begin{abstract}
Swearing words or curse are a part of the communication that exists in a language. Javanese and Lampung languagewhich live side by side in the Lampung region as one of the transmigration destinations are subjects of pragmatic which highlight the swearing words in non-formal communication. This article discusses swearing words in Javanese and Lampung in general. This qualitative descriptive study used the method of elicitation (used DCT) and agih by listening, note-taking technique, and interview. Prime data in form of both languages spoken by respondents. Secondary data in the form of studies that have been conducted become a starting point for studies in this article aimed at describing the types of Javanese and Lampung language swearing words and their functions in non-formal communication. Beside, the purpose of this article is uncovering the implicatures of swearing words in the two languages which have difference local tradition and comparing the structure of swearing words that are built up in the expressions of swearing words. After analyzing the data, the result shows that not all cursing came from the ten classifications defined in two languages. The ten classifications show that curses in Javanese were more complex and varied, while curses in Lampung were limited to certain classifications. The implication of all swearing in two languages, both Javanese and Lampung, was an expression of resentment, anger, and disappointment. However, the use of cursing without reference implicates the diverting conversation.
\end{abstract}

Keywords: swearing words, speech act, Javanese, Lampung language

\begin{abstract}
Abstrak
Umpatan atau sumpah serapah merupakan bagian dari komunikasi yang ada dalam sebuah bahasa. Bahasa Jawa dan bahasa Lampung-yang hidup berdampingan di wilayah Lampung sebagai salah satu daerah tujuan transmigrasi- menjadi objek kajian pragmatik yang menyoroti umpatan yang ada dalam komunikasi nonformal. Artikel ini membahas umpatan dalam bahasa Jawa dan bahasa Lampung secara umum. Penelitian berjenis deskriptif kualitatif ini menggunakan metode elisitasi (menggunakan (Discourse Compeltion Task) DCT) dan agih dengan teknik simak, catat, dan wawancara. Data primer berupa tuturan dua bahasa oleh responden. Data sekunder berupa penelitian-penelitian yang pernah dilakukan menjadi titik tolak kajian dalam artikel yang bertujuan mendeskripsikan jenis-jenis umpatan bahasa Jawa dan bahasa Lampung dan fungsinya di dalam komunikasi nonformal. Selain itu, tujuan dari artikel ini adalah mengungkap implikatur yang ada dalam tindak tutur berupa umpatan dalam dua bahasa daerah yang memiliki tradisi yang berbeda dengan membandingkan struktur umpatan yang terbangun dalam pengungkapan umpatan. Setelah dilakukan telaah data didapatkan hasil bahwa tidak semua umpatan bersumber sepuluh klasifikasi yang ditetapkan ada di dua bahasa. Pada sepuluh klasifikasi menunjukkan bahwa umpatan dalam bahasa Jawa lebih kompleks dan beragam, sementara umpatan dalam bahasa Lampung terbatas pada beberapa klasifikasi tertentu. Implikatur yang ada pada semua umpatan di dua bahasa, baik Jawa dan Lampung adalah pengungkapan kekesalan, kemarahan, dan kekecewaan. Namun, pada penggunaan umpatan tanpa referen merupakan implikatur untuk mengalihkan pembicaraan.
\end{abstract}

Kata-Kata kunci: umpatan, tindak tutur, bahasa Jawa, bahasa Lampung 


\section{PENDAHULUAN}

Keanekaragaman budaya Indonesia memunculkan banyak ragam kosakata dan istilah yang dipakai dalam komunikasi, salah satunya penggunaan umpatan atau ucapan berupa makian. Bentuk-bentuk umpatan dalam berbagai bahasa di nusantara menunjukkan betapa kayanya Indonesia akan ragam tuturan. Umpatan atau swearing words menjadi salah satu objek kajian yang menarik untuk diungkapkan. Artikel ini membahas umpatan dalam bahasa Jawa dan bahasa Lampung. Penulis membatasi objek kajian pada bahasa Jawa standar dan bahasa Lampung dialek Nyow agar terlihat jenisjenis umpatan dan fungsinya serta implikatur tindak tutur berupa umpatan yang ada dalam kedua bahasa tersebut. Penulis menelaah umpatan atau makian dalam bahasa Jawa berdasarkan alasan yang sangat mendasar, yaitu bahasa Jawa merupakan salah satu bahasa daerah di Indonesia yang memiliki jumlah penutur yang cukup besar dan tersebar di hampir seluruh wilayah Indonesia. Berdasarkan sensus penduduk 2010, penutur bahasa Jawa sebesar 31,79\% dari penduduk Indonesia. (BPS, 2010)

Selain bahasa Jawa, penulis juga menelaah umpatan atau makian dalam bahasa Lampung, khususnya dialek Nyow. Dr. Van Royen membagi bahasa Lampung menjadi dua dialek, yakni dialek Api dan Nyow (Wahyuni, 2009, hlm. xiv). Hal tersebut dilandasi oleh penguasaan penulis terhadap bahasa Lampung masih terbatas pada dialek tersebut. Latar belakang lainnya terkait pemilihan objek kajian berupa bahasa Lampung dialek Nyow adalah adanya anggapan yang menyatakan bahwa bahasa Lampung dialek Nyow tersebut memiliki lingkup cakupan yang sangat terbatas karena dituturkan di wilayah pedalaman yang tingkat mobilitasnya tidak setinggi dialek Api. Lampung merupakan salah satu kantong bahasa utama di Indonesia selain yang ada di Jawa Tengah dan Jawa Timur (BPS, 2010). Hal tersebut merupakan dampak dari transmigrasi penduduk Jawa yang dilakukan sejak 1905 (Andrews, 1979 dalam Suyanto). Mereka "ditempatkan" di wilayah-wilayah pedalaman Lampung yang mayoritas menuturkan bahasa Lampung dialek Nyow. Berdasarkan alasan tersebut, penulis hendak membandingkan penggunaan umpatan atau makian di kedua bahasa daerah yang memiliki riwayat sejarah yang cukup signifikan dalam artikel ini.

Sebuah tulisan tentu saja tidak bermula dari ketiadaan. Artikel ini didasari oleh beberapa penelitian terdahulu yang membahas tentang berbagai macam bentuk umpatan dan makian. Telah banyak tulisan mengenai umpatan dalam bahasa Jawa. Sebagai contoh artikel Setiawan (2016) yang berjudul "Bahasa Umpatan Kuli Panggul Bawang di Pasar Legi Surakarta (Kajian Pragmatik)" yang mendeskripsikan jenisjenis umpatan yang dituturkan oleh para kuli panggul bawang yang ada di Pasar Legi, Kota Surakarta, Jawa Tengah. Temuan Setiawan yang termaktub dalam artikelnya menunjukkan bahwa sebagian besar orang yang bekerja sebagai kuli panggul bawang di Pasar Legi Surakarta memiliki latar belakang ekonomi dan pendidikan yang rendah. Katakata umpatan yang keluar dari mulut para kuli panggul tersebut secara umum merupakan bentuk pelampiasan kekesalan atau kekecewaan karena sebagian besar kebutuhan mereka tidak tercukupi secara maksimal. Ditinjau dari lingkup latar peristiwa berupa pasar, tindak tutur berupa umpatan sudah biasa didengar dan bukan hal yang aneh lagi di kalangan kuli panggul dan masyarakat pada umumnya. Artikel Setiawan juga mengungkapkan jenis-jenis umpatan yang digunakan oleh para kuli panggul tersebut berupa kata, frasa, dan klausa yang memiliki fungsi marah, menyesal, kesal, menghina atau mengejek, heran, kecewa, dan simbol keakraban. Namun, Setiawan tidak mengungkapkan implikatur apa yang ada dalam tindak tutur umpatan-umpatan yang dilontarkan para kuli panggul tersebut. 
Wijana (2008) menulis "Kata-Kata Kasar dalam Bahasa Jawa". Temuan Wijana adalah kata-kata kasar dalam bahasa Jawa yang dituturkan berdasarkan beberapa konteks dalam komunikasi, yakni ketika berbicara, makan dan minum, tidur, pergi, dan mati. Konseptualisasi makna kata-kata kasar dalam bahasa Jawa menurut Wijana ditautkan dengan keadaan lingkungan sekitar penutur dan petutur. Daya metaforis dan pemadanan dengan sifat binatang melalui penggunaan kosakata yang berhubungan dengan anggota tubuh dan perilaku binatang tak pelak digunakan dalam pengungkapan kata-kata kasar tersebut. Waristha (2014) menulis "Makian dalam Komentar Video Klip Smash di Youtube (Kajian Pragmatik) yang memiliki beberapa temuan di antaranya terkait tuturan, validitas, dan implikatur pada komentar warganet di kanal youtube yang menampilkan video klip grup vokal Smash. Waristha menemukan empat implikatur dalam komentar bernada makian tersebut, yakni tersinggung, kesal, marah, dan memberi peringatan.

Pengungkapan perasaan melalui umpatan terkadang juga dapat ditelisik dari jenis kelamin penututurnya. Sebagaimana dalam artikel Anggreni dkk. (2019) yang berjudul "Penggunaan Umpatan di Twitter berdasarkan Gender di Pilkada Sumatera Utara 2018". Temuan Anggreni dkk. Menunjukkan bahwa umpatan dan makian di media sosial didominasi oleh warganet berjenis kelamin laki-laki. Umpatan yang ditunjukkan laki-laki menggambarkan bentuk kekecewaan, kesal, dan marah pada pelaksanaan pemilihan kepala daerah. Umpatan atau makian dapat juga berfungsi sebagai bentuk sindiran dan ungkapan keakraban sebagaiana yang dijabarkan oleh Putra (2012) dalam artikel yang berjudul "Bentuk dan Fungsi Kata Umpatan pada Komunikasi Informal di Kalangan Siswa SMA Negeri 3 Surabaya: Kajian Sosiolinguistik". Putra menyebutkan bahwa selain sebagai ungkapan kekesalan dan rasa marah, umpatan juga dapat berfungsi sebagai bentuk keakraban suasana dan sapaan, ungkapan kagum, keterkejutan, dan sindiran.

Artikel yang membahas bentuk dan jenis umpatan dalam bahasa Lampung sepengetahuan penulis belum ada, khususnya dialek Nyow. Setelah melakukan beberapa pencarian di platform Google terdapat sebuah tulisan berjudul "Pemakaian Bahasa Lampung di Daerah Rajabasa" yang ditulis Agustina (2015) yang mendeskripsikan penggunaan bahasa Lampung oleh masyarakat yang tinggal di wilayah Rajabasa, Bandarlampung. Agustina menggambarkan bahwa bahasa Lampung, khususnya dialek Api masih dituturkan di wilayah administratif Bandarlampung yang notabene sudah sangat jarang didengar komunikasi dalam bahasa Lampung, baik dialek Api maupun dialek Nyow. Namun, belum ada satu pun penelitian pragmatik terkait tindak tutur berupa umpatan dalam bahasa Lampung, khususnya dialek Nyow. Oleh sebab itu, penulis tertarik untuk mengungkapkan implikatur yang ada dalam tindak tutur berupa umpatan dalam dua bahasa daerah tersebut dengan membandingkan struktur umpatan yang terbangun dalam pengungkapan umpatan.

\section{LANDASAN TEORI}

Gagasan seseorang tidak muncul secara tiba-tiba tanpa adanya latar belakang pemikiran. Sebuah penelitian tentu dipicu oleh pemikiran sebelumnya. Begitu pun dengan artikel ini. Ahli-ahli pragmatik telah mendefinisikan pragmatik dengan berbagai fenomena yang ada. Secara umum, pragmatik merupakan kajian bidang linguistik yang menelaah pemakaian bahasa tertentu untuk keperluan komunikasi dalam masyarakat (Jauhari, 2018). Pada tahun 1993, Leech menyatakan bahwa pragmatik mempunyai dua cakupan utama dalam telaahnya, yakni Pragmalinguistik dan Sosiopragmatik. Pandangan Pragmalinguistik merupakan kajian pragmatik yang lebih dominan membahas 
sisi linguistik yang berupa sumber-sumber langsung yang tersedia dalam bahasa tertentu untuk menyatakan ilokusi. Selain itu, kajian Pragmalinguistik banyak berkorelasi dengan tata bahasa dalam bahasa yang dikaji. Pandangan Sosiopragmatik menelaah aspek pragmatik yang dititikberatkan pada jenis kebudayaan, masyarakat, dan kondisi-kondisi sosial tertentu. Selain itu, Sosiopragmatik merupakan perpaduan Sosiologi dan Pragmatik. Jadi, artikel ini dapat dikategorikan dalam kajian Sosiopragmatik karena objek kajiannya adalah umpatanumpatan atau makian yang ada dalam komunikasi masyarakat Jawa dan Lampung.

Pragmatik juga tercakupi dalam bidang linguistik fungsional, yakni kajian tentang fungsi bahasa dalam kehidupan sosial masyarakat berupa efek dari penggunaan bahasa tertentu dalam suatu masyarakat tertentu. Menurut Jakobson, model fungsi bahasa (dalam kerangka Linguistik Fungsional) dapat dibedakan pada tataran konteks, pengirim, penerima, kontak atau channel, kode umum, dan pesan yang disampaikan. Tataran dalam komunikasi menurut Jakobson tersebut dapat diartikan bahwa pragmatik dalam kerangka linguistik fungsional dapat dibedakan menjadi tiga tipe, yakni tipe komunikator, tipe konteks, dan tipe penggunaan bahasa yang tecermin dalam bagan model linguistik fungsional berikut ini.

Bagan 1

Model Lingusitik Fungsional Jakobson

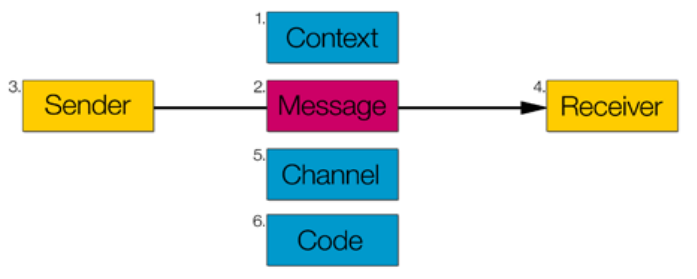

Keterangan:

1. referensial berupa informasi kontekstual

2. poetic berupa autotelic

3. emotif berupa ekspresi diri

4. konatif berupa bentuk perintah atau vokatif

5. fatis berupa mengecek channel

6. metalingual

Selain Jakobson, pragmatik dalam lingkup linguistik fungsional menutut Karl Bühler dalam Sprachtheorie (1934) yang diakses pada Innis R.E. (1982) Bühler's Axiomatic Project. In: Karl Bühler Semiotic Foundations of Language Theory. Springer, Boston, MA. menyatakan bahwa bahasa sebagai alat atau media penutur untuk menginformasikan pada khalayak tentang suatu hal.

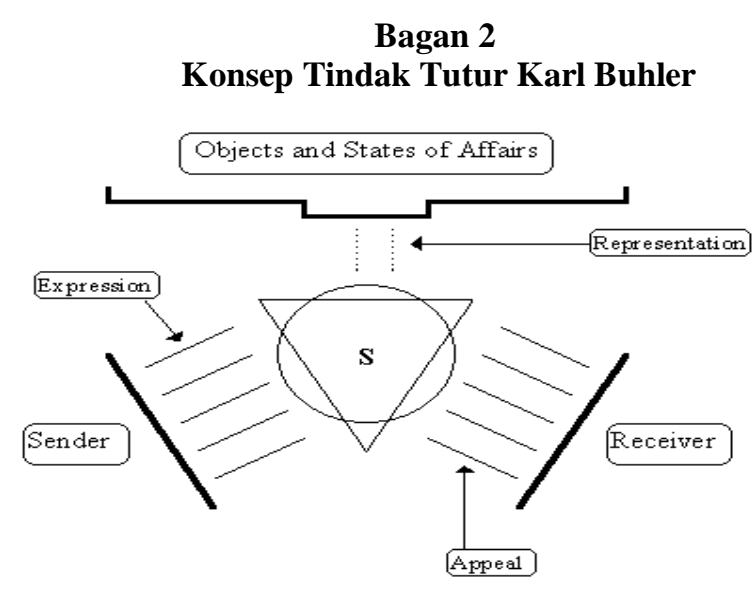

Dari bagan tersebut, Bühler mengusulkan konsep tindak tutur, yakni semua tuturan konkret yang merupakan hal penting dalam peristiwa tutur. Konsep tersebut banyak dimanfaatkan oleh peneliti pragmatik dalam mengkaji tindak tutur. Hal lain yang menjadi sumbangan Bühler dalam bidang pragmatik antara lain konsep deiktik, konteks pada tuturan sebagai tindak sosial, deiksis linguistik yang terletak pada pernyataan posisi penutur "saat ini saya di sini" yang merupakan titik tolak pembagian peran yang bersifat temporal dan orientasi, serta koordinasi sosial di antara penutur dan mitra tutur. Pragmatik memiliki keterkaitan dengan bidang semantik (Leech, 1993, Hlm. 6) yang kemudian dikenal dengan istilah semantisme, pragmatisme, dan komplementarisme (Leech, 1993 dalam Waristha). 
Kamus Besar Bahasa Indonesia V Daring memaknai umpatan atau makian sebagai 'kata keji yang diucapkan karena marah dan sebagainya'. Umpatan dalam bahasa daerah sangat beragam, begitu pun yang ada di Jawa dan Lampung. Borin (2009 dalam Suyanto, 2017) memosisikan bahasa Jawa pada tingkatan ke-12 dunia untuk penutur terbanyak bahasa ibu. Bahasa Jawa yang mengenal undha usuk atau stratifikasi berdasarkan kelas sosial juga tak lepas dari bentuk umpatan-umpatan dalam pola komunikasi dan tindak tuturnya. Setidaknya ada tiga ragam bahasa yang digunakan dalam bahasa Jawa secara umum, yakni ngoko, madya, dan krama. Umpatan atau dalam istilah bahasa Jawa disebut dengan pisuhan, biasanya berupa leksikon bermakna kasar lazimnya berada pada ragam bahasa ngoko (periksa Wijana, 2008). Sebuah umpatan atau makian dalam bahasa Jawa akan terdengar menggelikan ketika umpatan disampaikan dalam ragam krama, sebagai contoh kalimat berikut ini:

(1) Wah, wekdal yahketen kok sampun dhahar?

|wah, waktu saat ini (ketika komunikasi berlangsung) kok sudah makan|

'Wah, masih jam segini kok sudah makan?'

(2) Wadhuh, yahmene kok wis mbadhog? Aduh, saat ini (ketika komunikasi berlangsung) kok sudah makan| 'Waduh, masih jam segini kok sudah makan (dalam porsi besar)?

Kedua contoh kalimat tersebut bermakna sama, tetapi menggunakan ragam bahasa Jawa yang berbeda. Kalimat (1) merupakan ragam krama yang mengandung ciri implikatur kekecewaan dalam pilihan kata yahketen 'waktu tertentu' yang dianggap belum pantas untuk makan, misalnya pagi buta. Namun, juga bergantung pada konteks apa kalimat tersebut dituturkan. Kata dhahar (1) dan mbadhog (2) memiliki makna yang sama, yakni 'makan'. Namun, “rasa' kedua leksikon tersebut berbeda. Kalimat (1) adalah ragam halus dan kalimat (2) mengandung kata kasar sebagai bentuk kekesalan terhadap tindakan seseorang yang dianggap mengecewakan, menjengkelkan, dan tidak tepat secara umum pada budaya Jawa.

Lain halnya dengan bahasa Jawa, dalam bahasa Lampung secara umum tidak terdapat bentuk stratifikasi atau lapis bahasa. Pembedaan leksikon yang menunjukkan bentuk honorifik atau penghormatan pada bahasa Lampung secara umum hanya terdapat pada tataran sapaan saja. Intonasi atau nada bicara penutur bahasa Lampung yang cenderung bernada tinggi akan semakin tinggi ketika tuturan yang diungkapkan mengandung umpatan atau makian. Adapun contoh kalimat yang mengandung unsur umpatan atau ngopok (Wahyuni, 2010, hlm.154) dalam bahasa Lampung adalah sebagai berikut.

(3) Dugug, sapou sai ngemban retah dijou, wah!

|(sebutan) setan, siapa yang membuang sampah di sini wah (ungkapan kekesalan)

'Setan, siapa yang membuang sampah di sini, ya!'

(4) Kak gelek sabaghkeu jou, oiy. Dugus...dugus...!

|KLITIK (sudah) habis sabarku ini, (prakategorial) dugus (ungkapan kekesalan) |

'Sudah habis kesabaran saya ini, lah...Setan...setan!'

Dua contoh kalimat dalam bahsa Lampung dialek Nyow yang mengandung umpatan tersebut menunjukkan keegaliteran budaya Lampung yang tidak membedakan penggunaan leksikon dalam tuturan yang mengandung umpatan. Namun, ciri pembedanya kebanyakan hanya terdapat pada intonasi dan repetisi. Kata umpatan atau makian dapat dikatakan sebagai salah satu ragam kata afektif yang digunakan dalam komunikasi. Umpatan atau makian muncul akibat tindakan seseorang atau adanya sebuah kejadian tertentu yang memunculkan respons tertentu sehingga terpantik daya pantulnya atau pelampiasannya (Sudaryanto dkk, 1982, 
Hlm. 146). Umpatan atau makian biasanya digunakan seseorang yang sedang dalam keadaan marah dan labil perasaannya. Namun, ada juga umpatan yang digunakan sebagai bentuk keakraban satu sama lain dalam komunikasi. Keunikan tiap-tiap bentuk ungkapan dalam bahasa Jawa (ragam standar) dan bahasa Lampung (dialek Nyow) tersebut menarik untuk dikaji lebih lanjut dalam segi pragmatiknya.

\section{METODE}

Data yang digunakan dalam penelitian ini adalah data primer berupa umpatan bahasa Lampung dialek Nyow yang penulis peroleh dari informan melalui sambungan telepon dan pesan tertulis (karena kondisi pandemi Covid-19 tidak memungkinkan untuk melakukan pengambilan data di lapangan) dan data sekunder berupa penelitian-penelitian terdahulu yang mengandung umpatan dalam bahasa Jawa. Tindak tutur berupa umpatan dalam dua bahasa daerah tersebut menjadi objek sentral dalam artikel ini agar dapat mengungkapkan implikatur yang melingkupinya sebagai salah satu hal dalam telaah pragmatik. Secara daring, penulis juga menggunakan metode DCT (Discourse Completion Task) seperti yang dicetuskan Blum-Kulka et. al (1989) dan Rintell dan Mitcell (1989). DCT yang penulis gunakan dalam penelitian ini memanfaatkan borang daring google form yang memungkinkan informan untuk mengisi kuesioner berkaitan dengan bahasa Lampung secara daring dan bahasa Jawa secara langsung dengan kuesioner fisik. Bentuk DCT yang penulis gunakan sangat sederhana berupa dialog pendek dan deskripsi singkat tentang situasi tertentu yang berhubungan dengan bentukbentuk umpatan dalam bahasa Lampung dan bahasa Jawa tersebut. Selain itu, penulis juga menggunakan intuisi penulis sebagai penutur asli bahasa Jawa dan bahasa Lampung dialek Nyow.

Data-data umpatan dua bahasa daerah tersebut dicatat dan ditelaah secara rinci dengan kartu data yang didapat dari jawaban para responden melalui borang google form dan lembar kuesioner fisik. Pertanyaan pada responden adalah yang berhubungan denga napa yang diucapkan responden ketika mendapat pernyataan yang tidak sopan dan sebagainya. Bungin (2007, Hlm. 107--123) menyatakan metode dan teknik pengumpulan data dapat berupa pengamatan langsung atau elisitasi, wawancara, perekaman, simak-catat, dan dokumentasi, tetapi karena kondisi wabah ini penulis menggunakan metode elisitasi dengan teknik penyebaran DCT dan kuesioner. Sumber data dalam artikel ini adalah umpatan-umpatan dalam bahasa Jawa dan bahasa Lampung dialek Nyow yang dituturkan responden, terdiri atas empat orang (dua orang penutur jati bahasa Jawa dan dua orang penutur jati bahasa Lampung dialek Nyow).

Adapun kriteria pemilihan responden didasarkan pada beberapa hal, yakni penutur jati berusia produktif, alat ucap sempurna, kompetensi sedang, dan mobilitas yang tidak terlalu tinggi.

Data berupa umpatan-umpatan bahasa Jawa dan bahasa Lampung dikumpulkan dan dikelompokkan berdasarkan bentuk dan fungsinya dalam komunikasi. Data-data umpatan yang berupa kartu data yang penulis peroleh dari hasil wawancara langsung dan daring, serta isian kuesioner tersebut kemudian ditelaah dengan ancangan pragmatik agar dapat diungkapkan implikatur tindak tutur berupa umpatan dalam dua bahasa. Penyajian hasil telaah dilakukan secara formal berupa tabel dan informal berupa penjelasan menyeluruh terhadap telaah tersebut.

\section{PEMBAHASAN}

Implikatur tindak tutur yang dibahas dalam artikel ini berupa umpatan bahasa Jawa (pisuhan) dan bahasa Lampung (ngopok). Telaah implikatur didasarkan pada klasifikasi bentuk umpatan yang sudah dijabarkan menjadi sepuluh jenis. Pragmatik 
memiliki keterkaitan dengan bidang semantik (Leech, 1993, Hlm. 6) yang kemudian dikenal dengan istilah semantisme, pragmatisme, dan komplementarisme (Leech, 1993 dalam Waristha).

Bentuk umpatan ada tiga, yakni berupa kata, frasa, dan klausa. Klasifikasi jenis umpatan dalam bahasa Jawa ada 10 (Djatmika, 2016, Hlm. 25 dalam Gunawan). Klasifikasi yang diusulkan Djatmika tersebut akan digunakan juga untuk mengungkap implikatur ungkapan bahasa Lampung. Adapun klasifikasi jenis dan fungsi umpatan dalam bahasa Jawa dan bahasa Lampung didasarkan pada sepuluh hal, yakni umpatan yang bersumber pada leksikon anggota tubuh, nama binatang, nama profesi bermakna rendah, nama bagian pohon atau tempat, nama anggota keluarga, nama orang, umpatan tanpa referen, kondisi intelegensi, dan kesehatan mental. Kesepuluh klasifikasi tersebut dijabarkan dalam bentuk tanyaan dengan metode DCT yang memanfaatkan borang google form yang dijawab oleh responden berbahasa Jawa dan berbahasa Lampung.

\section{a. Anggota Tubuh}

Umpatan dalam bahasa Jawa dan bahasa Lampung sering menggunakan anatomi tubuh manusia. Hal tersebut terlihat pada contoh kalimat yang mengandung umpatan sebagai berikut

\section{Data 1}

Ketika Anda dan teman Anda sedang bercengkerama, tiba-tiba terlihat ada seekor kecoa di sekitar Anda. Umpatan apa jika teman Anda disuruh memakan kecoa?

Responden 2 dan 3 sebagai penutur Jawa menyatakan kalimat yang mengandung umpatan sebagai berikut:

1a. Woo, ra nggenah. Pangan utekmu njebluk! Panganen dhewe kono!

(ungkapan kekesalan), tidak jelas. Makan otakmu meledak! Makan sendiri sana
'Woo, tidak masuk akal. Otakmu meledak (menyuruh) makan! Makan saja sendiri sana!'

1b. Lambemu njedhir! Mosok coro kon mangan. Utekmu semlenget, cah!

bibirmu njedhir (ungkapan kekesalan). Masa kecoa disuruh makan. Otak kamu panas dingin, anak

Bibirmu bengkak! masa kecoa dimakan. Otakmu mendidih.

Reaksi yang ditunjukkan kedua responden pada pernyataan kuesioner 1 menggunakan anggota tubuh manusia berupa otak dan bibir sebagai kata umpatan untuk menunjukkan kekesalan pada pemberi perintah. Selain itu, kedua responden juga mengungkapkan bentuk umpatan lain dalam bahasa Jawa yang menggunakan anggota tubuh manusia (yang diikuti kata ganti milik -mu) sebagai pelampiasan kekesalan atas perintah untuk memakan kecoa, yakni ndhasmu 'kepalamu', gundhulmu '(kepala) gundulmu', dengkulmu 'lututmu', matamu 'matamu', bathukmu 'jidatmu', lambemu 'bibirmu', cocotmu 'mulutmu', cangkemmu 'mulutmu', udelmu 'pusarmu', utekmu 'otakmu', raimu 'wajahmu', rирати 'mukamu', silitmu 'anusmu', entutmu 'kentutmu', taimu 'tahimu', dan bolmu 'wasirmu'.

Penulis juga menanyakan hal yang sama pada penutur bahasa Lampung dengan pertanyaan yang sama pada responden 1 dan 4 yang merupakan penutur bahasa Lampung dialek Nyow.

1c. Kan ulahmeu. Otok kak cadang! |makan olehmu. Otak KLITIK (sudah) rusak|

'Makan saja sendiri olehmu. Dasar, otak rusak!'

1d. Uleume pecoh kedey, ngayun ulun mengan kecoak!

|kepalamu pecah PARTIKEL, menyuruh orang makan kecoal 'kepalamu pecah, ya. Masa menyuruh orang makan kecoa' 
Reaksi yang ditunjukkan responden 1 dan 4 menunjukkan pemanfaatan anggota tubuh manusia sebagai umpatan, yakni otak dan kepala. Pada kalimat 1c responden menyatakan konsep semantik otok cadang 'otak rusak'. Selain itu, responden 1 dan 4 juga menyatakan umpatan lain yang menggunakan anggota tubuh sebagai umpatan, yakni matou botou 'mata buta', cuping bolot 'telinga congek', pudak binatang 'wajah hewan', sek 'kemaluan perempuan/ vagina', smanget 'kemaluan perempuan/ vagina', teling 'kemaluan lakilaki/ penis', kacukndai 'kemaluan laki-laki/ penis', dan atei buyuk 'hati busuk'. Hal tersebut mengandung implikatur kekesalan, kemarahan, dan perasaan tidak terima.

b. Nama binatang

Umpatan dalam bahasa Jawa dan bahasa Lampung menggunakan nama binatang. Hal tersebut terlihat pada contoh kalimat yang mengandung umpatan sebagai berikut

\section{Data 2}

Ketika berdebat dengan teman Anda, terjadi ketegangan karena ada masalah keluarga. Umpatan apa yang Anda ucapkan jika Anda menanggapi teman Anda yang menghina keluarga Anda?

Responden 2 dan 3 sebagai penutur Jawa menyatakan kalimat yang mengandung umpatan sebagai berikut:

2 a. Asu, kowe! Ora sah ngenyek kluwargaku, ora ono urusan karo dhapurmu!

|anjing kamu! Tidak usah menghina keluargaku, tidak ada urusan dengan (diri) kamul

'Anjing! Tidak usah menghina keluargaku, tidak ada urusan denganmu!'

2b. Rene taktapuk lambemu, celeng ya...salah apa kluwargaku ro raimu!

|ke sini kutampar bibirmu, babi hutan ya...salah apa keluargaku pada (wajah)|

'Sini, kutampar bibirmu, celeng ya...salah apa keluargaku padamu!'.
Reaksi yang ditunjukkan kedua responden pada pernyataan kuesioner 2 menggunakan nama binatang berupa asu 'anjing' dan celeng 'babi hutan' sebagai kata umpatan untuk menunjukkan kemarahan pada seseorang. Selain itu, kedua responden juga mengungkapkan bentuk umpatan lain untuk "melengkapi" pelampiasan kemarahannya dengan kata dhapur 'diri' (yang jadi referen) dan rai 'muka' yang bermakna kasar dalam bahasa Jawa. Umpatan lain bersumber nama binatang yang diungkapkan responden yakni kirik 'anak anjing', jangkrik 'jangkerik', tekek 'tokek', sapi 'sapi', genjik 'anak babi', wedhus 'kambing', dan sebagainya.

Penulis juga menanyakan hal yang sama pada penutur bahasa Lampung dengan pertanyaan yang sama pada responden 1 dan 4 yang merupakan penutur bahasa Lampung dialek Nyow.

2c. Nyow maksudmeu kak ngejek ulun tohouku? Babui, keghou nikeu!

lapa maksudmu KLITIK (sudah) menghina orang tuaku? Babi, kera kamu| 'Apa maksudmu menghina orang tuaku? Babi, monyet kamu!'

2d. Lamen nikeu banei, dang ngejek kluwargoukeu! Aseu, babui, keghou yeh! jika kamu berani, jangan mengejek keluargaku! Anjing, babi, kera PARTIKEL (ungkapan kekesalan) | 'Jika kamu berani, jangan menghina keluargaku! Anjing, babi, monyet, ya!'

Reaksi yang ditunjukkan responden 1 dan 4 menunjukkan pemanfaatan nama binatang sebagai umpatan, yakni anjing, babi, dan monyet. Selain itu, responden 1 dan 4 juga menyatakan umpatan lain yang menggunakan anggota tubuh sebagai umpatan, yakni ulai 'ular' dan bohou 'buaya'. Hal tersebut mengandung implikatur kemarahan dan rasa tidak terima.

c. Nama profesi bermakna rendah 
Umpatan dalam bahasa Jawa dan bahasa Lampung menggunakan nama profesi bermakna rendah. Maksud dari bermakna rendah adalah profesi yang dianggap memiliki tingkat sosial yang rendah di masyarakat. Hal tersebut terlihat pada contoh kalimat yang mengandung umpatan sebagai berikut

\section{Data 3}

Anda dan teman Anda sedang berjalan kaki selepas hujan, tiba-tiba datang mobil yang berjalan kencang dan melewati genangan air. Umpatan apa yang Anda ucapkan jika seragam Anda kotor karena terciprat lumpur jalan ketika ada mobil melintas dengan kecepatan tinggi?

Responden 2 dan 3 sebagai penutur Jawa menyatakan kalimat yang mengandung umpatan sebagai berikut:

3a. Bajingan ...ra nduwe utek!

|bajingan tidak punya otak|

'Bajingan, tak ada otak!'

3b. Woo, sontoloyo! Ra urus!

| (ungkapan kekesalan), sontoloyo tidak urus|

'Woo, sontoloyo! Tidak tahu diri!'

Reaksi yang ditunjukkan kedua responden pada pernyataan kuesioner 3 menggunakan nama profesi bermakna negatif, yakni bajingan 'kusir sado atau gerobak sapi' dan sontoloyo 'penggembala bebek' sebagai kata umpatan untuk menunjukkan kekesalan. Namun, perlu digarisbawahi, bahwa makna dua kata tersebut sudah bergeser menjadi negatif. Selain itu, kedua responden juga mengungkapkan bentuk umpatan lain dalam bahasa Jawa yang menggunakan nama profesi bermakna negatif lain sebagai pelampiasan kekesalannya tersebut, yakni copet 'copet' dan lonthe 'pelacur'.

Penulis juga menanyakan hal yang sama pada penutur bahasa Lampung dengan pertanyaan yang sama pada responden 1 dan
4 yang merupakan penutur bahasa Lampung dialek Nyow.

3c. Kampang! Makkou otok!

|anak haram! Tidak punya otak|

'kampang! Tak ada otak!'

3d. Bajingan! Ulun lawang!

| (ungkapan kekesalan) orang gila |

'bajingan! Orang gila'

Reaksi yang ditunjukkan responden 4 menunjukkan nama profesi bermakna negatif sebagai umpatan, yakni bajingan, tetapi responden 1 menggunakan umpatan kampang 'anak hasil zina'. Umpatan bajingan dalam bahasa Lampung ada interferensi dari bahasa Jawa karena proses akulturasi budaya. Selain kosakata tersebut, responden 1 dan 4 menjawab tidak ada lagi umpatan lain yang bersumber pada nama profesi bermakna negatif. Hal tersebut mengandung implikatur kekesalan, kemarahan, dan tidak terima.

d. Nama bagian pohon atau tempat

Umpatan dalam bahasa Jawa dan bahasa Lampung menggunakan nama bagian pohon atau tempat. Hal tersebut terlihat pada contoh kalimat yang mengandung umpatan sebagai berikut

Data 4

Anda mendapatkan tugas menulis ucapan di sebuah kartu, tetapi ada tulisan yang salah. Umpatan apa yang Anda ucapkan ketika mendapati tulisan Anda salah?

Responden 2 dan 3 sebagai penutur Jawa menyatakan kalimat yang mengandung umpatan sebagai berikut:

4a. Asem, salah meneh!

|asam, salah lagi|

'Huh, salah lagi'

4b. Hasyem tenan, malah salah, huh ndadak mbaleni.

asam betul, malah salah, huh mendadak harus mengulangi|

'Huh, malah salah, terpaksa mengulang' 
Reaksi yang ditunjukkan kedua responden pada pernyataan kuesioner 4 menggunakan anggota nama bagian pohon berupa asem 'asam' dan hasyem, yang merupakan bentuk plesetan dari asem sebagai kata umpatan untuk menunjukkan kekecewaan dan penyesalan sepadan dengan kata huh.

Penulis juga menanyakan hal yang sama pada penutur bahasa Lampung dengan pertanyaan yang sama pada responden 1 dan 4 yang merupakan penutur bahasa Lampung dialek Nyow. Namun, kedua responden menyatakan tidak ada umpatan yang bersumber pada nama bagian pohon atau tempat.

e. Nama peralatan makan

Umpatan dalam bahasa Jawa dan bahasa Lampung menggunakan nama peralatan makan. Hal tersebut terlihat pada contoh kalimat yang mengandung umpatan sebagai berikut

\section{Data 5}

Teman Anda main ke rumah Anda ketika Anda baru selesai mandi, tapi ia mengejek Anda belum mandi. Umpatan apa yang Anda ucapkan jika teman Anda tidak percaya Anda sudah mandi?

Responden 2 dan 3 sebagai penutur Jawa menyatakan kalimat yang mengandung umpatan sebagai berikut:

\section{5a. Cething, ah!}

|bakul nasi, PARTIKEL|

'cething ah!'

Reaksi yang ditunjukkan responden 2 pada pernyataan kuesioner 5 menggunakan nama peralatan makan berupa cething 'bakul tempat nasi' yang diikuti oleh partikel ah sebagai kata umpatan untuk menunjukkan kekecewaan yang bernada sangkalan dan rasa tidak suka pada pernyataan petutur. Sementara itu, responden 3 tidak menjawab.

Penulis juga menanyakan hal yang sama pada penutur bahasa Lampung dengan pertanyaan yang sama pada responden 1 dan 4 yang merupakan penutur bahasa Lampung dialek Nyow. Namun, kedua responden tidak memberikan jawaban.

f. Nama anggota keluarga

Umpatan dalam bahasa Jawa dan bahasa Lampung menggunakan nama anggota keluarga. Hal tersebut terlihat pada contoh kalimat yang mengandung umpatan sebagai berikut

\section{Data 6}

Anda dan teman Anda makan di sebuah kantin, tetapi ketika pelayan memberikan tagihan, teman Anda beralasan tidak punya uang. Umpatan apa yang Anda ucapkan ketika seorang teman meminta Anda membayari makanannya di kantin? Responden 2 dan 3 sebagai penutur Jawa menyatakan kalimat yang mengandung umpatan sebagai berikut:

6a. Lha mbahmu! Kowe sing mangan aku sing mbok kon mbayar!

|PARTIKEL nenek kamu! Kamu yang makan aku yang kamu suruh membayar|. 'Lah, nenekmu! Kamu yang makan, aku yang harus bayar!'

6b. Makmu, ah...ra jaman mbayarmbayari!

|ibu kamu PARTIKEL. Tidak zaman membayari|

'Ibumu, ah. Bukan zaman membayari!'

Reaksi yang ditunjukkan kedua responden pada pernyataan kuesioner 6 menggunakan nama anggota keluarga berupa $m b a h$ 'nenek/kakek' dan mak 'ibu' sebagai kata umpatan untuk menunjukkan kekesalan.

Penulis juga menanyakan hal yang sama pada penutur bahasa Lampung dengan pertanyaan yang sama pada responden 1 dan 4 yang merupakan penutur bahasa Lampung dialek Nyow. Namun, kedua responden memberikan jawaban yang sama yakni ndai 'ibu'.

6b. Ndai, ah...jaman tanou makkou duwit, kidah!

|ibu PARTIKEL zaman sekarang tidak ada uang PARTIKEL| 
'Oh Ibu. Zaman sekarang masa tak punya uang sih!'

\section{g. Nama orang}

Umpatan dalam bahasa Jawa dan bahasa Lampung sering menggunakan nama orang. Hal tersebut terlihat pada contoh kalimat yang mengandung umpatan sebagai berikut

\section{Data 7}

Sepulang kerja, Anda berharap dapat beristirahat di kamar karena sangat Lelah, tapi ketika masuk kamar, Anda mendapati kamar sangat berantakan. Umpatan apa yang Anda ucapkan ketika mendapati kamar Anda berantakan akibat ulah adik Anda?

Responden 2 dan 3 sebagai penutur Jawa menyatakan kalimat yang mengandung umpatan sebagai berikut:

7a. Hiih, Paijo siji ki ncen njaluk dijantur, kok!

| (ungkapan kekesalan) Paijo (nama orang) satu ini memang minta digantung kakinya PARTIKEL|

'Hih, Paijo satu ini memang minta dihajar, kok!'

7b. Woalah, Mukidi...Mukidi...kurang ajar tenan, kok!

|PARTIKEL Mukidi (nama orang) kurang ajar benar PARTIKEL|

'Oalah, Mukidi...Mukidi...benar-benar kurang ajar, kok!'

Reaksi yang ditunjukkan kedua responden pada pernyataan kuesioner 7 menggunakan nama orang, yakni Paijo dan Mukidi sebagai kata umpatan untuk menunjukkan kekesalan. Selain itu, kedua responden juga mengungkapkan bentuk umpatan lain dalam bahasa Jawa yang menggunakan nama orang sebagai pelampiasan kekesalan, yakni Mukiyo, Samin, Paijem, dan nama-nama lain yang terkesan ndesa 'kampungan'.

Penulis juga menanyakan hal yang sama pada penutur bahasa Lampung dengan pertanyaan yang sama pada responden 1 dan 4 yang merupakan penutur bahasa Lampung dialek Nyow. Namun, kedua responden tidak memberikan jawaban.

h. Umpatan tanpa referen

Umpatan dalam bahasa Jawa dan bahasa Lampung sering menggunakan umpatan tanpa referen. Hal tersebut terlihat pada contoh kalimat yang mengandung umpatan sebagai berikut

\section{Data 8}

Ketika ada pertemuan keluarga, semua handai taulan berkumpul. Tiba-tiba ada saudara jauh Anda yang sebaya dengan Anda menanyakan pada Anda kapan menikah, padahal ia tahu Anda belum memiliki calon pendamping. Umpatan apa yang Anda ucapkan jika Anda ditanya kapan menikah?

Responden 2 dan 3 sebagai penutur Jawa menyatakan kalimat yang mengandung umpatan sebagai berikut:

8a. sikak, ah!

(ungkapan kekesalan sekaligus keakraban) PARTIKEL|

'sikak, ah!'

8b. prek, ah. Rasah marai emosi!

| (ungkapan kekesalan sekaligus keakraban) PARTIKEL tidak usah membuat emosi|

'prek, ah. Jangan memancing emosi!'

Reaksi yang ditunjukkan kedua responden pada pernyataan kuesioner 8 menggunakan umpatan tanpa referen berupa sikak dan prek untuk menunjukkan kekesalan dan berupaya mengalihkan fokus pembicaraan. Kedua umpatan tersebut pada konteks komunikasi juga menunjukkan bentuk keakraban. Apabila penutur dan mitra tutur belum saling mengenal, umpatan tersebut tidak akan muncul. Selain itu, kedua responden juga mengungkapkan bentuk umpatan lain dalam bahasa Jawa yang menggunakan umpatan tanpa referen sebagai pelampiasan kekesalan dan upaya mengalihkan topik pembicaraan, yakni pret, cemet, mbel, dan mblegedhes. 
Penulis juga menanyakan hal yang sama pada penutur bahasa Lampung dengan pertanyaan yang sama pada responden 1 dan 4 yang merupakan penutur bahasa Lampung dialek Nyow. Namun, kedua responden tidak memberikan jawaban apapun.

i. Kondisi intelegensi

Umpatan dalam bahasa Jawa dan bahasa Lampung sering menggunakan anatomi tubuh manusia. Hal tersebut terlihat pada contoh kalimat yang mengandung umpatan sebagai berikut

\section{Data 9}

Teman Anda datang ke rumah Anda ketika Anda sedang sibuk menyusun mainan lego menjadi istana. Ketika akan menyelesaikan susunan lego, tiba-tiba teman Anda menepuk pundak Anda dan membuat Anda kaget sehingga istana lego Anda berantakan. Umpatan apa yang Anda ucapkan ketika mendapati teman Anda mengageti Anda sehingga mengacaukan lego yang sudah Anda susun dengan susah payah?

Responden 2 dan 3 sebagai penutur Jawa menyatakan kalimat yang mengandung umpatan sebagai berikut:

9a. Woalah, péthuk péthuk...wis takgawe ngaya-ngaya malah bubrah!

|PARTIKEL (ungkapan kekesalan) bodoh...sudah aku buat susah payah malah bubrah|

'Oalah, péthuk péthuk...sudah susah payah kubuat malah buyar!’

9b. Pekoke, cah cah...ra nggenah tenan cah iki, ora ngajeni wong!

bodoh anak tidak jelas benar anak ini, tidak menghargai orang|

'Bodohnya. Benar-benar tidak tahu diri anak ini, tidak menghargai orang lain!

Reaksi yang ditunjukkan kedua responden pada pernyataan kuesioner 9 menggunakan kondisi intelegensi sebagai kata umpatan untuk menunjukkan kekesalan dan kekecewaan. Selain itu, kedua responden juga mengungkapkan bentuk umpatan lain dalam bahasa Jawa yang menggunakan kondisi intelegensi sebagai pelampiasan kekesalan, yakni oon 'bloon', once 'bloon yang diplesetkan', oneng 'nama karakter yang dianggap bodoh', PA (pekok ajek) 'bodoh yang menetap', koplak 'gila', koplo 'tidak waras', goblok 'bodoh', dan idiot 'idiot'.

Penulis juga menanyakan hal yang sama pada penutur bahasa Lampung dengan pertanyaan yang sama pada responden 1 dan 4 yang merupakan penutur bahasa Lampung dialek Nyow.

9c. Sanak lugugh, makkou rasan kedey? Posikkeu kak cadang, wah!

anak bodoh, tidak ada pekerjaan PARTIKEL? mainanku sudah rusak PARTIKEL|

'Anak bodoh, iseng sekali ya? Mainanku jadi rusak, kan!'

\section{9d. Mati bodouno! \\ |sangat bodoh| \\ 'Alangkah bodohnya!'}

Reaksi yang ditunjukkan responden 1 dan 4 menunjukkan pemanfaatan kondisi inteligensi sebagai umpatan, yakni lugugh dan bodou yang sama-sama bermakna 'bodoh'.

j. Kesehatan Mental

Umpatan dalam bahasa Jawa dan bahasa Lampung sering menggunakan kondisi mental. Hal tersebut terlihat pada contoh kalimat yang mengandung umpatan sebagai berikut

\section{Data 10}

Anda membaca koran yang di halaman utamanya adalah berita tentang korupsi yang dilakukan anggota dewan. Umpatan apa yang Anda ucapkan ketika membaca berita tentang tindak korupsi?

Responden 2 dan 3 sebagai penutur Jawa menyatakan kalimat yang mengandung umpatan sebagai berikut:

10 a. Edan tenan, ora nrima ing pandum.

Wis sugih tapi isih kurang wae. 
gila benar, tidak menerima di pembagian. Sudah kaya tetapi masih kurang saja|

'Benar-benar gila, tidak bersyukur. Sudah kaya tapi masih merasa kurang.'

10b. Wong ra waras, wis ngerti korupsi ki dosa, malah dibaleni!

lorang tidak sehat, sudah mengerti korupsi itu berdosa, malah diulangi|

Orang tidak waras, sudah tahu korupsi itu dosa, kok diulangi!'

Reaksi yang ditunjukkan kedua responden pada pernyataan kuesioner 10 menggunakan kesehatan mental, yakni edan dan ra waras sebagai kata umpatan untuk menunjukkan kekesalan sekaligus kekecewaan terhadap perilaku koruptor. Selain itu, kedua responden juga mengungkapkan bentuk umpatan lain dalam bahasa Jawa yang menggunakan kesehatan mental sebagai pelampiasan kekesalan, yakni gendheng 'tidak waras', kenthir 'gila', kurang sak canthing 'kurang satu canting'.

Penulis juga menanyakan hal yang sama pada penutur bahasa Lampung dengan pertanyaan yang sama pada responden 1 dan
4 yang merupakan penutur bahasa Lampung dialek Nyow.

10 c. Ulun serakah, lawang!

lorang serakah, (ungkapan kekesalan) gila|

'orang yang serakah, gila!'

10 d. Kak tudau, mak besokur!

| (PARTIKEL) gila, tidak bersyukur|

'Sudah gila, tidak bersyukur!'

Reaksi yang ditunjukkan responden 1 dan 4 menunjukkan penggunaan Kesehatan mental sebagai umpatan, yakni lawang dan tudau. Selain itu, responden 1 dan 4 juga menyatakan umpatan lain yang menggunakan kesehatan mental sebagai umpatan, yakni mesiser 'sangat genit', mabok 'mabuk', ta'on 'sangat gila'.

Kesepuluh kategori umpatan dalam bahasa Jawa dan bahasa Lampung tersebut menyiratkan adanya pengaruh kognitif yang melingkupi kehidupan di sekitar masyarakat Jawa dan Lampung. Adapun jenis umpatan dalam dua bahasa daerah tersebut dapat dilihat pada tabel berikut ini.

Tabel 1

Umpatan-Umpatan dalam Bahasa Jawa dan Bahasa Lampung

\begin{tabular}{|c|c|c|c|c|c|c|c|c|c|c|c|c|c|c|c|c|c|c|c|}
\hline \multicolumn{2}{|c|}{ Anggota Tubuh } & \multicolumn{2}{|c|}{$\begin{array}{c}\text { Nama } \\
\text { Binatang }\end{array}$} & \multicolumn{2}{|c|}{$\begin{array}{c}\text { Nama Profesi } \\
\text { bermakna } \\
\text { rendah }\end{array}$} & \multicolumn{2}{|c|}{$\begin{array}{c}\text { Nama } \\
\text { bagian } \\
\text { pohon }\end{array}$} & \multicolumn{2}{|c|}{$\begin{array}{c}\text { Nama } \\
\text { peralatan } \\
\text { makan }\end{array}$} & \multicolumn{2}{|c|}{$\begin{array}{c}\text { Nama } \\
\text { Anggota } \\
\text { Keluarga } \\
\end{array}$} & \multicolumn{2}{|c|}{$\begin{array}{l}\text { Nama } \\
\text { orang }\end{array}$} & \multicolumn{2}{|c|}{$\begin{array}{c}\text { Umpatan } \\
\text { tanpa referen }\end{array}$} & \multicolumn{2}{|c|}{$\begin{array}{c}\text { Kondisi } \\
\text { Intelejensia }\end{array}$} & \multicolumn{2}{|c|}{$\begin{array}{c}\text { Kesehatan } \\
\text { Mental }\end{array}$} \\
\hline Jawa & Lpg & Jawa & Lpg & Jawa & $\begin{array}{c}\text { Lamp } \\
\text { ung }\end{array}$ & $\begin{array}{c}\text { Jaw } \\
\text { a }\end{array}$ & $\begin{array}{c}\mathrm{L} \\
\mathrm{pg}\end{array}$ & $\begin{array}{c}\text { Jaw } \\
\text { a }\end{array}$ & $\begin{array}{c}\mathrm{L} \\
\mathrm{pg}\end{array}$ & Jawa & $\begin{array}{c}\mathrm{L} \\
\mathrm{pg}\end{array}$ & $\begin{array}{c}\text { Jaw } \\
\text { a }\end{array}$ & $\begin{array}{c}\mathbf{L} \\
\mathbf{p g}\end{array}$ & Jawa & $\begin{array}{c}\mathrm{L} \\
\mathrm{pg}\end{array}$ & $\begin{array}{c}\text { Jaw } \\
\text { a }\end{array}$ & Lpg & Jawa & Lpg \\
\hline utekmu & $\begin{array}{l}\text { otok } \\
\text { cadan } \\
g\end{array}$ & asu & $\begin{array}{l}b a b \\
u i\end{array}$ & $\begin{array}{l}\text { bajing } \\
\text { an }\end{array}$ & $\begin{array}{l}\text { kampa } \\
n g\end{array}$ & $\begin{array}{l}\text { ase } \\
\mathrm{m} / \\
\text { hasy } \\
\text { em }\end{array}$ & & $\begin{array}{l}\text { cethi } \\
n g\end{array}$ & - & $\begin{array}{l}\text { mbah } \\
m u\end{array}$ & nd & $\begin{array}{l}\text { Paij } \\
o\end{array}$ & - & sikak & - & $\begin{array}{l}\text { peth } \\
u k\end{array}$ & $\begin{array}{l}\text { lugu } \\
\text { gh }\end{array}$ & edan & $\begin{array}{l}\text { lawa } \\
n g\end{array}$ \\
\hline $\begin{array}{l}\text { lambem } \\
u\end{array}$ & $\begin{array}{l}\text { uleu } \\
\text { pecoh }\end{array}$ & $\begin{array}{l}\text { celen } \\
g\end{array}$ & $\begin{array}{l}\text { kegh } \\
\text { ou }\end{array}$ & $\begin{array}{l}\text { sontol } \\
\text { oyo }\end{array}$ & $\begin{array}{l}\text { bajing } \\
\text { an }\end{array}$ & & & & & $\begin{array}{l}\text { mak } \\
m u\end{array}$ & & $\begin{array}{l}\text { Muk } \\
\text { idi }\end{array}$ & & pret & & $\begin{array}{l}\text { pek } \\
\text { ok }\end{array}$ & $\begin{array}{l}\text { bod } \\
\text { ou }\end{array}$ & $\begin{array}{l}\text { ra } \\
\text { waras } \\
\end{array}$ & $\begin{array}{l}\text { tuda } \\
u\end{array}$ \\
\hline $\begin{array}{l}\text { ndhasm } \\
u\end{array}$ & $\begin{array}{l}\text { matau } \\
\text { botou }\end{array}$ & kirik & aseu & copet & & & & & & & & $\begin{array}{l}\text { Muk } \\
\text { iyo }\end{array}$ & & prek & & oon & & $\begin{array}{l}\text { gendh } \\
\text { eng }\end{array}$ & $\begin{array}{l}\text { mesi } \\
\text { ser }\end{array}$ \\
\hline $\begin{array}{l}\text { gundhul } \\
\mathrm{mu}\end{array}$ & $\begin{array}{l}\text { cuping } \\
\text { bolot }\end{array}$ & $\begin{array}{l}\text { jangk } \\
\text { rik }\end{array}$ & ulai & lonthe & & & & & & & & $\begin{array}{l}\text { Sami } \\
n\end{array}$ & & cemet & & $\begin{array}{l}\text { onc } \\
e\end{array}$ & & $\begin{array}{l}\text { kenthi } \\
r\end{array}$ & $\begin{array}{l}m a b \\
o k\end{array}$ \\
\hline $\begin{array}{l}\text { dhengk } \\
\text { ulmu }\end{array}$ & $\begin{array}{l}\text { pudak } \\
\text { binata } \\
\text { ng }\end{array}$ & tekek & $\begin{array}{l}\text { boh } \\
\text { ou }\end{array}$ & germo & & & & & & & & $\begin{array}{l}\text { Paij } \\
\text { em }\end{array}$ & & mbel & & $\begin{array}{l}\text { one } \\
\text { ng }\end{array}$ & & $\begin{array}{l}\text { kuran } \\
\text { g sak } \\
\text { canthi } \\
\text { ng }\end{array}$ & ta'on \\
\hline matamu & sèk & sapi & & & & & & & & & & & & $\begin{array}{l}\text { mblege } \\
\text { dhes }\end{array}$ & & $P A$ & & & \\
\hline $\begin{array}{l}\text { cocotm } \\
u\end{array}$ & $\begin{array}{l}\text { smang } \\
\hat{e} t\end{array}$ & $\begin{array}{l}\text { genji } \\
k\end{array}$ & & & & & & & & & & & & & & $\begin{array}{l}\text { idio } \\
t\end{array}$ & & & \\
\hline $\begin{array}{l}\text { cangke } \\
\text { mти }\end{array}$ & teling & $\begin{array}{l}\text { wedh } \\
\text { us }\end{array}$ & & & & & & & & & & & & & & $\begin{array}{l}\text { kopl } \\
a k\end{array}$ & & & \\
\hline silitmu & $\begin{array}{l}\text { kacuk } \\
\text { ndai }\end{array}$ & & & & & & & & & & & & & & & $\begin{array}{l}\text { kopl } \\
o\end{array}$ & & & \\
\hline raimu & $\begin{array}{l}\text { atei } \\
\text { buyuk }\end{array}$ & & & & & & & & & & & & & & & $\begin{array}{l}\text { gobl } \\
o k \\
\end{array}$ & & & \\
\hline ruрати & & & & & & & & & & & & & & & & & & & \\
\hline $\begin{array}{l}\text { udhelm } \\
u\end{array}$ & & & & & & & & & & & & & & & & & & & \\
\hline entutmu & & & & & & & & & & & & & & & & & & & \\
\hline
\end{tabular}




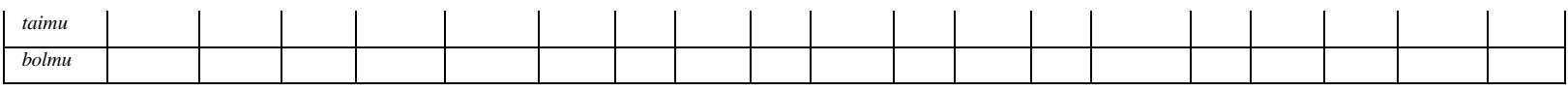

Tabel tersebut menggambarkan bentuk-bentuk umpatan dalam bahasa Jawa dan bahasa Lampung yang terlihat jelas ketimpangan jumlah leksikon yang dimiliki. Umpatan-umpatan dalam bahasa Jawa lebih dominan dan beragam dibandingkan dengan umpatan dalam bahasa Lampung. Hal tersebut mengindikasikan daya ungkap yang lebih banyak pada bahasa Jawa dibandingkan dengan daya ungkap dalam bahasa Lampung. Unsur paling dominan terlihat pada umpatan bahasa Jawa pada kategori umpatan berdasarkan anggota tubuh. Terdapat lima belas leksikon umpatan dalam bahasa Jawa, yakni utek 'otak', lambe 'bibir', ndhas 'kepala', gundhul 'kepala', dhengkul 'lutut', mata 'mata', cocot 'mulut', cangkem 'mulut', udel 'pusar', silit 'anus', rai 'wajah', rupa 'muka', entut 'kentut', tai 'tahi', bol 'wasir' dan kesemuanya diikuti pronomina $-m u$ yang menunjukkan kekesalan pada petutur. Sementara itu, umpatan bahasa Lampung terdiri atas sepuluh leksikon, yakni otok 'otak', uleu 'kepala', matou 'mata', cuping 'telinga', pudak 'wajah', sek 'vagina', smanget 'vagina', teling 'penis', kacukndai 'kelamin laki-laki', atei 'hati'.

Kategori umpatan bersumber nama binatang juga terlihat beragam. Terdapat delapan umpatan dalam bahasa Jawa, yakni asu 'anjing', celeng 'babi hutan', kirik 'anak anjing', jangkrik 'jangkerik', tekek 'tokek', sapi 'sapi', genjik 'anak babi', wedhus 'kambing'. Sementara itu, terdapat lima umpatan dalam bahasa Lampung, yakni babui 'babi', keghou 'monyet/kera', aseu 'anjing', ulai 'ular', bohou 'buaya'. Kategori umpatan bersumber nama profesi bermakna rendah pada bahasa Jawa terdapat 4 leksikon, yakni bajingan 'kusir sado atau gerobak sapi', sontoloyo 'penggembala bebek', copet 'copet', lonthe 'pelacur'. Umpatan bahasa Lampung pada kategori nama profesi bermakna rendah hanya ada dua, yakni kampang 'anak haram' dan bajingan 'bajingan'.

Kategori umpatan bersumber bagian pohon/tempat menunjukkan leksikon pada bahasa Jawa terdapat satu, yakni asem/ hasyem 'asam', sementara pada bahasa Lampung tidak ditemukan. Hal tersebut juga ditunjukan pada kategori umpatan bersumber nama peralatan makan yang hanya terdapat satu leksikon pada bahasa Jawa, yakni cething 'tempat nasi' dan tidak ditemukan dalam bahasa Lampung. Kategori umpatan bersumber nama anggota keluarga pada bahasa Jawa terdapat dua leksikon, yani, mbahmu 'nenek/kakekmu', makmu 'emakmu', sementara dalam bahasa Lampung hanya ditemukan leksikon ndai 'ibu'.

Kategori umpatan bersumber nama orang ditemukan lima leksikon dalam bahasa Jawa, yakni Paijo, Mukidi, Mukiyo, Samin, dan Paijem. Nama-nama tersebut muncul secara gethok tular 'dari mulut ke mulut' yang tidak dapat dipastikan asal atau latar belakang penggunaan nama-nama tersebut secara etimologis, sementara dalam bahasa Lampung tidak ditemukan. Kategori umpatan bersumber kondisi intelegensi terdapat sepuluh leksikon dalam bahasa Jawa, yakni pethuk, pekok, oon, once, oneng, PA (pekok ajek), idiot, koplak, koplo, goblok. Sementara dalam bahasa Lampung hanya terdapat dua leksikon, yakni lugugh dan bodou yang sama-sama bermakna 'bodoh'. Kategori umpatan bersumber kesehatan mental, baik bahasa Jawa maupun bahasa Lampung terdapat lima leksikon, yakni edan, ra waras, gendheng, kenthir, kurang sak canthing yang kesemuanya bermakna 'gila', sementara dalam bahasa Lampung, yakni lawang 'gila', tudau 'gila', mesiser 'genit', mabok 'mabuk', ta'on 'gila'. 


\section{PENUTUP}

Setelah dilakukan telaah data didapatkan hasil bahwa tidak semua umpatan yang bersumber sepuluh kategori atau klasifikasi yang ditetapkan dimiliki oleh bahasa Jawa dan bahasa Lampung. Sepuluh klasifikasi menunjukkan bahwa umpatan dalam bahasa Jawa lebih kompleks dan beragam, sementara umpatan dalam bahasa Lampung terbatas pada beberapa klasifikasi tertentu. Implikatur yang ada pada semua umpatan di dua bahasa, baik Jawa dan Lampung adalah pengungkapan kekesalan, kemarahan, dan kekecewaan. Namun, pada penggunaan umpatan tanpa referen ada implikatur untuk mengalihkan pembicaraan dan bentuk keakraban karena penutur dan mitra tutur sudah saling mengenal.

Penelitian pragmatik memang sangat menarik untuk dilakukan. Indonesia yang memiliki keanekaragaman budaya merupakan samudera data yang dapat dianalisis dengan pisau pragmatik mutakhir. Kesempatan untuk menulis tentang bentuk, jenis, dan fungsi umpatan yang dihubungkan dengan teori pragmatik lintas bahasa dan budaya masih sangat terbuka untuk diolah menjadi sajian temuan baru dalam khazanah ilmu linguistik fungsional.

\section{DAFTAR PUSTAKA}

Agustina, Eka Sofia (2015). "Pemakaian Bahasa Lampung di Daerah Rajabasa". Lokabahasa 6/1: 38-52. https://www.researchgate.net/publicatio n/331836383_PEMAKAIAN_BAHAS A_LAMPUNG_DI_DAERAH_RAJAB ASA

Anggreni, Likha Sari, dkk. (2019). "Penggunaan Kata Umpatan di Twitter berdasarkan Gender di Pilkada Sumatera Utara”. Jurnal Kajian Komunikasi, 7/1: 121-132

Bungin, B. (2007) Penelitian Kualitatif, Komunikasi, Ekonomi, Kebijakan Publik, dan Ilmu Sosial Lainnya. Jakarta: Kencana.
Blim-Kulka et.al. (1989). "Investigating Cross-Cultural Pragmatics: An Introductory Overviews". Cross Cultural Pragmatics Request and Apologies. New Jersey: Ablex Publishing Corporation Norwood

Jauhari, Edy. (2018). "Alat-Alat Kesantunan Kritik dalam Masyarakat Jawa Surabaya: Kajian Pragmatik". Mozaik Humaniora, 18/2: 167-177

Kridalaksana, Harimurti. (2011). Kamus Linguistik. Jakarta: Gramedia

Leech, Geoffrey. (1993). Prinsip-Prinsip Pragmatik. Diterjemahkan oleh M.D.D. Oka. Jakarta: Universitas Indonesia.

Putra, Rachmad Rizky (2012). "Bentuk dan Fungsi Kata Umpatan pada Komunikasi Informal di Kalangan Siswa SMA Negeri 3 Surabaya: Kajian Sosiolinguistik": 93-105. https://studylibid.com/doc/510026/bent uk-dan-fungsi-kata-umpatan-pada (diunduh pada 2 April 2021 pukul 16.33)

Rintell, Ellen dan Mitchell, Candace J. (1989). "Studying Request and Apologies: An Inquiry into Methode". Cross Cultural Pragmatics Request and Apologies. New Jersey: Ablex Publishing Corporation Norwood

Setiawan, Nugroho (2016). "Bahasa Umpatan Kuli Panggul Bawang di Pasar Legi Surakarta (Kajian Pragmatik). Skripsi, Universitas Negeri Semarang

Sudaryanto, Marsono, Widya Kirana, I Dewa Putu Wijana. (1982). Kata Afektif dalam Bahasa Jawa. Laporan Penelitian. Yogyakarta: Balai Penelitian Bahasa.

Suyanto dan Mujid F.A. (2017). "Pemakaian Bahasa Jawa di Provinsi Lampung Berdasar Data Sensus Penduduk 2010". Jurnal Nusa, Vol 12, No. 3

Waristha, Puri Noor. (2014). "Makian dalam Komentar Video Klip Smash di Youtube (Kajian Pragmatik)". Bandung: Repository Universitas Pendidikan Indonesia. 
Totobuang, Vol. 9, No. 1, Juni 2021: 75—90

https://ejournal.upi.edu/index.php/BS_ Antologi_Ind/article/view/637/473

Wijana, I Dewa Putu (2008) "Kata-Kata Kasar dalam Bahasa Jawa". Humaniora 20/3: 249-256.

Wahyuni, Tri dkk. (2010). Kamus Dwibahasa Lampung-Indonesia. Bandarlampung: Kantor Bahasa Provinsi Lampung.

\section{SUMBER INTERNET:}

http://www.signosemio.com/jakobson/functi ons-of-language.asp (diakses pada 5 Januari 2021)

Innis R.E. (1982) Bühler's Axiomatic Project. In: Karl Bühler Semiotic
Foundations of Language Theory. Springer, Boston, MA. https://doi.org.proxy.undip.ac.id/10.10 07/978-1-4757-0923-0_1

Sensus Penduduk 2010, Badan Pusat Statistik.

https://www.bps.go.id/publication/201 0/12/23/b0adeb45e05c3db10ac99f33/s tatistik-indonesia-2010.html

Kamus Besar Bahasa Indonesia V Daring. https://kbbi.kemdikbud.go.id

https://doi.org.proxy.undip.ac.id/10.1007/97 8-1-4757-0923-0_1 